\title{
Using Diary Methods to Study Marital and Family Processes
}

\author{
Jean-Philippe Laurenceau \\ University of Miami
}

\author{
Niall Bolger \\ New York University
}

\begin{abstract}
Diary methods allow researchers to study marital and family processes within the context of daily life in a way that is not possible with more traditional methods. The authors review applications of diary designs in marital and family research and detail the types of research questions that can uniquely be asked of dyadic/family diary data. Technological developments for the use of electronic palm-top devices for implementing diary methods are also reviewed. Additionally, the authors discuss specific issues relevant to the analysis of diary data that come from dyads or families. Last, the authors raise unresolved issues and directions for future research in the use of diary methods for studying marital and family processes.
\end{abstract}

Keywords: diary methods, research design, marital processes, family processes

Marital and family relationships have long been studied using a variety of methodologies, such as longitudinal assessment of measures of family functioning, surveys of family members across various community and social contexts, and laboratory observation of family member interactions. As a result of these methods, theoretical and empirical advances have been made in several areas related to marital and family process, including the identification of predictors of the quality and stability of marriage over time (Karney \& Bradbury, 1995), destructive marital interaction patterns and influences on marital and family functioning (Gottman \& Notarius, 2000), and determinants of child development and family socialization (Parke, 2004). In this article, we describe and discuss a methodological strategy, known as diary methods, that is being used with increasing frequency in social and behavioral research and that can also contribute to advances in the study of marriage and the family.

Experience sampling, daily diaries, interaction records, momentary sampling, and real-time data capture all refer to a class of methodologies for examining everyday experience known broadly as diary methods (for a review, see Bolger, Davis, \& Rafaeli, 2003). In some forms of diary methods, participants provide assessments of thoughts, feelings, and behavior several times during a day when signaled

Jean-Philippe Laurenceau, Department of Psychology, University of Miami; Niall Bolger, Department of Psychology, New York University.

Preparation of the manuscript was supported by National Institute of Mental Health (NIMH) Grant K01-MH4779 to JeanPhilippe Laurenceau and NIMH Grant R01-MH60366 to Niall Bolger. We thank Pat Shrout for his conceptual and methodological contributions and S. T. Calvin for his moral support.

Correspondence concerning this article should be addressed to Jean-Philippe Laurenceau, Department of Psychology, University of Miami, 459 Flipse Building, Coral Gables, FL 33146. E-mail: jlaurenceau@miami.edu by a particular event (e.g., a conflict) or by an electronic device (e.g., pager). In other diary designs, daily assessments of affect and behavior are obtained over several days or several weeks. In a dyadic diary study examining relationship processes in marriage, each spouse might provide within-day (e.g., upon being randomly signaled throughout the day) or across-day (e.g., once daily for 21 consecutive days) reports on events, behaviors, and experiences that have occurred within the everyday context of the relationship.

The primary benefit of examining marital and family processes using diary methods is that they permit examination of relationship events and experiences in their natural, spontaneous context and often reduce the likelihood of retrospection by minimizing the amount of time between the experience of an event and the account of the event (Bolger et al., 2003; Stone, Shiffman, \& DeVries, 1999; Wheeler \& Reis, 1991). Moreover, diary methods allow researchers to tap more dynamic aspects of marital and family relationship experiences that might be obfuscated when using traditional designs that involve cross-sectional or widely spaced longitudinal assessments.

The purpose of this article is to provide an introduction to the application of diary methods for studying marriage and family processes. Although more general discussions of diary methods for individual applications can be found in Bolger et al. (2003) and Reis and Gable (2000), we focus here on methodological and data analytic issues that would be of more relevance to marital and family researchers. In the first section, we describe some applications of diary methods in marital and family research, highlight some of the methodological advantages, and discuss technological issues. We also detail three broad types of research questions specific to dyadic processes that can be addressed using diary methods. In the second section, we discuss related data analytic issues specific to working with diary data that come from dyads or families. Last, we raise unresolved issues and directions for 
future research when using diary methods to study phenomena that are of interest to marriage and family researchers.

\section{Applications and Methodological Issues}

Diary and related methods largely started in the field of personality and social psychology. Some of the earliest work was done by Csikszentmihalyi and colleagues (Csikszentmihalyi \& Larson, 1984; Csikszentmihalyi, Larson, \& Prescott, 1977), who studied emotional processes in the daily lives of adolescents, and Diener and colleagues (Diener \& Larsen, 1984; Diener \& Emmons, 1985), who studied the patterns of mood across situations in daily experience. One of the first applications of diary methods to the study of marriage was by Wills, Weiss, and Patterson (1974), who examined the link between daily pleasurable and displeasurable behaviors (over 14 days) and global ratings of marital satisfaction in 7 nondistressed married couples. Since then, there have been a small, but growing, number of studies that have taken advantage of diary procedures to investigate specifically marital and family phenomena (e.g., Perrez, Schoebi, \& Wilhelm, 2000).

We provide a few examples to highlight the kinds of applications of diary methods for substantive questions in marital and family research. In one diary study, daily measures of workload and marital behaviors were obtained from a group of air traffic controllers and their spouses over a 3-day period (Repetti, 1989). Results of this intervalcontingent recording study indicated that days with high workload were followed by increased social withdrawal and decreased expression of anger in the presence of spousal support. In another study, researchers used daily reports of family tension and satisfaction from parents in both distressed and nondistressed families over a 2-week period (Margolin, Christensen, \& John, 1996). In particular, results indicated that, in distressed families, marital tension and conflict can spread into parent-child and sibling-sibling relationships and vice versa, whereas this spread of tension among family subsystems did not occur in nondistressed families. In a more recent study, mothers and fathers completed a diary assessment after conflictual marital interactions to examine the effects of constructive and destructive conflict on their children's negative emotion and behavior (Cummings, Goeke-Morey, Papp, \& Dukewich, 2002). What all these examples have in common is the ability of the researchers to tap contingencies of relationship events and experiences in their everyday, spontaneous context.

\section{Advantages and Strengths of Diary Methods}

There are several strengths and advantages associated with the use of diary methods for studying marital and family process. Below, we highlight some of the more pertinent ones.

First, diary methods allow researchers to determine whether processes observed in the lab also occur in natural settings as well as the contextual boundaries for their occurrence. For example, marital conflict that is generated through prompts and manipulation in the lab does not generally occur in the same context/situation as in life at home (Larson, Richards, \& Perry-Jenkins, 1994). In early work by Gottman (1979), it was observed that marital conflicts in the lab are underestimates of behavior when compared to recordings made in couples' homes. In contrast to the control that comes with laboratory manipulations and settings, diary methods focus on the "natural manipulations" of daily life. Diary methods can be a way for marriage and family researchers to generalize and extend findings to everyday settings.

Second, diary methods allow marital and family researchers to get closer to the microlevel processes to complement existing macrolevel and longer-term longitudinal findings. For example, neuroticism, a proneness to negative emotional reactivity and liability, has been repeatedly implicated as a personality trait related to poor global marital outcomes (Adams, 1946; Bentler \& Newcomb, 1978; Karney \& Bradbury, 1997, 2000; Kelly \& Conley, 1987) and has emerged as one of the strongest predictors of marital satisfaction and stability in reviews of the literature (Karney \& Bradbury, 1995). However, past studies have tended to focus on macrolevel outcomes, such as marital satisfaction and behavioral negativity, but not on the day-to-day behaviors and emotions that eventually contribute to these macrolevel outcomes. Using a multilevel daily process paradigm, Bolger and colleagues (Bolger \& Schilling, 1991; Bolger \& Zuckerman, 1995) found that interpersonal stressors have a significant impact on daily distress and daily negative affect. Moreover, theorists have posited that enduring individual vulnerabilities (e.g., neuroticism) and stressful events interact with each other to affect couple processes, which in turn affect relationship satisfaction. Thus, the effect of neuroticism on the quality of marital relationships over time likely occurs within the ongoing context of stressors (see Holmes \& Murray, 1996; Karney \& Bradbury, 1995). Diary methods can be used to elucidate mechanisms through which distal factors (e.g., personality) may influence more proximal interpersonal outcomes.

Third, diary methods allow researchers to obtain information about contextual/situational factors within which behavior, cognition, and emotion of interest in marriage occurs. In a study investigating the occurrence, antecedents, and consequences of stressful marital interactions, distressed and nondistressed couples were asked to complete a diary at the end of each day for 14 days (Halford, Gravestock, Lowe, \& Scheldt, 1992). These researchers found that, for both distressed and nondistressed couples, particular settings, topics, and activities were associated with the occurrence of stressful interactions. For example, the most stressful conflictual marital interactions occurred in the kitchen and during weekdays and were linked to daily life stressors. Distressed couples reported a higher frequency and intensity of stressful interactions, fewer resolutions, and greater withdrawal after stressful interactions.

Fourth, utilizing a diary methodology can also allow researchers to tap into the process nature of interpersonal phenomenon by allowing for multiple measures of variables over time within a person, couple, or family. For example, 
Laurenceau, Feldman Barrett, and Rovine (in press) examined the intimacy process using daily diary reports from married couples. Cross-sectional assessments may impose a static-like quality to a more dynamic interpersonal process under investigation (Duck \& Sants, 1983). Moreover, hypotheses about within-person processes and hypotheses are tested all too often using between-subjects methods and data. Consider the following two scenarios for examining the link between daily stressful events and negative affect in husbands and wives. In the first, a researcher obtains stressor and emotion data at one point in time across several husbands and wives. In the second, stressors and emotion are measured at several occasions for a husband and wife. Will both these scenarios provide similar answers to the question? The answer is no. The first scenario is focused on interindividual variability and can only address whether husbands high in stressors also report higher levels of negative affect. In comparison, the second scenario is focused on intraindividual variability and can address whether a particular husband's stressors have an influence on his levels of negative affect. The links (parameterized as a beta weight or correlation) across these two scenarios do not have the same meaning and will often not be the same value. That is, links among variables at the between-person level may not be the same as links among within-person variables (Borsboom, Mellenbergh, \& van Heerden, 2003).

Last, we believe diary methods can provide a perspective that is different from, but complementary with, traditional marital and family research methods such as global selfreport and observation of behavior (Reis, 1994). All three methodological approaches (i.e., self-report, observation, and diary) can provide somewhat discrepant, but important, perspectives on the same interpersonal and family phenomena. Nevertheless, when compared to global self-report and observational approaches, marital and family researchers have made less use of diary methods for tapping the domain of ongoing daily experience. We believe that research combining two or three of these methodological approaches to address research questions will likely be stronger than research focusing only on one. In a study of mother-preschooler dyads, Repetti and Wood (1997) provided an interesting example of combining daily diary reports of job stress, behavioral observation of parent-child interactions, and self-report measures of trait anxiety, depression, and Type A personality to examine the effects of daily stress on parent-child interactions. The researchers found that daily work stress tends to lead to greater mother withdrawal in interactions at the end of the day rather than irritability and that this effect was stronger for mothers with high versus low Type A personality traits. This innovative combination of information from self-report, observation, and diary approaches is a direction that we encourage marital and family researchers to follow.

\section{Types of Research Questions}

Bolger et al. (2003) outlined three types of research questions that can be addressed using diary data on individuals. In Tables 1-3, we expand on this typology to the case of diary data on distinguishable dyads (e.g., wife vs. husband, caretaker vs. child), triads (mother, father, child), and larger groups. As will become clear as we progress through these tables, dyadic and family data allow investigators to ask important new questions that cannot be addressed in studies of individuals.

The advantage of restricting our focus to distinguishable dyads is that data analysis becomes considerably easier, and generalizing the questions and analyses to distinguishable triads, tetrads, and so forth is relatively straightforward (and where this is not the case, we alert the reader to any added complexities). However, it has the important drawback that we omit dyads (and larger groupings) in which there is no fixed role relationship between members (e.g., same-sex sibling relationships, gay and lesbian relationships). We refer those interested in the analysis of data from indistinguishable dyads to Gonzalez and Griffin (2000) and Kenny, Kashy, and Cook (2005).

Tables $1-3$ each contain three major sections. In the first section, we describe in the most general, abstract terms the research questions that can be addressed using diary data on dyads. In the second section, we restate the research questions as they apply to a concrete example, namely, a fictitious study of 100 husband-wife dyads, where each partner provides end-of-day diary reports on daily conflicts and moods for 7 days. The dependent variable we focus on is levels of end-of-day anger for husbands and wives, and predictor variables are time (day) and the occurrence of a conflict between both partners. Prior to data collection, half of the couples were randomized to an intervention group of participants who received a weekend-long spousal and social support workshop, and the other half received no intervention. In discussing Tables $1-3$, we focus on this concrete example, and we continue with it throughout the remainder of the article.

In the third section of Tables $1-3$, we describe the multilevel analysis model for the fictitious dataset and identify the parameters that are relevant to answering the specific research questions. This section is discussed in the data analysis section of the article. At this point, however, it is useful to have a general idea of the structure of the dataset. Table 4 depicts the data layout for two couples. For now, notice that each couple contributes 14 observations (lines of data) to the dataset and that there are columns indexing couple, intervention group, partner, day, and the dependent variable.

Aggregating over time: What is the mean and variability of $Y$ for members of the average dyad? The first type of question concerns aggregating over the time dimension of the diary data and characterizing the dependent variable for the average dyad. Referring to the concrete research questions in column 1 of Table 1 , the first questions pertain to average levels of the dependent variable, namely, what is the average daily anger for the husband and for the wife in the typical couple? Next are questions concerning variability over time: To what extent does the average husband's daily anger vary from 1 day to the next? and To what extent does the average wife's daily anger vary? Finally, there is a question that can only be addressed using a dyadic design: 
Table 1

Examples of Research Questions and Statistical Analysis for Time-Based Diary Studies: Aggregating Over Time

Abstract research questions

What is the average dyads's:

(a) average $\mathrm{Y}$ for member $\mathrm{A}$ average $\mathrm{Y}$ for member B

(b) variability in $\mathrm{Y}$ for member $\mathrm{A}$ variability in $\mathrm{Y}$ for member $\mathrm{B}$ covariation in member A's and member B's Y

What is the average couple's:

(a) average daily anger for husband average daily anger for wife

(b) day-to-day variability in H's anger day-to-day variability in W's anger

day-to-day covariation in H's and

W's anger
How much do dyads (co)vary from one another in:

(a) member A's average Y member B's' average $Y$ member A's and B's average $Y$ (covariance)

(b) member A's variability in Y member B's variability in $\mathrm{Y}$ covariation in member A's and member B's Y
What are the sources of between-dyad (co)variability in:

(a) member A's average Y member B's average $Y$ member A's and member B's average $Y$ (covariance)

(b) member A's variability in $Y$ member B's variability in $Y$ covariance in member A's and member B's $\mathrm{Y}$

Concrete research questions: Daily conflict study

How much do couples (co)vary from one another in:

(a) average daily anger for $\mathrm{H}$ average daily anger for $\mathrm{W}$ average daily anger for $\mathrm{H}$ and $\mathrm{W}$ (covariance)

(b) day-to-day variability in H's anger day-to-day variability in W's anger day-to-day covariation in H's and W's anger
Can intervention group explain between-couple (co)variability in:

(a) average daily anger for $\mathrm{H}$ average daily anger for $\mathrm{W}$ average daily anger for $\mathrm{H}$ and $\mathrm{W}$ (covariance)

(b) day-to-day variability in H's anger day-to-day variability in W's anger day-to-day covariation in H's and W's anger
Multilevel model

Level 1: Intercept for $\mathrm{H}$ and $\mathrm{W}$ Error variance for $\mathrm{H}, \mathrm{W}(\mathrm{b})$ $\mathrm{H}, \mathrm{W}$ error covariance (b)

Level 2: Intercept for $\mathrm{H}$ and $\mathrm{W}$ (a) Error variance for $\mathrm{H}, \mathrm{W}$ $\mathrm{H}, \mathrm{W}$ error covariance
Level 1: Intercept for $\mathrm{H}$ and $\mathrm{W}$ $\mathrm{H}, \mathrm{W}$ error variance by couple (b)

$\mathrm{H}, \mathrm{W}$ error covariance by couple (b)

Level 2: Intercept for $\mathrm{H}$ and $\mathrm{W}$ Error variance for $\mathrm{H}, \mathrm{W}(\mathrm{b})$ $\mathrm{H}, \mathrm{W}$ error covariance (b)
Level 1: Intercept for $\mathrm{H}$ and $\mathrm{W}$ $\mathrm{H}, \mathrm{W}$ error variance by group (b) $\mathrm{H}, \mathrm{W}$ error covariance by group (b)

Level 2: Intercept for $\mathrm{H}, \mathrm{W}$ by group (a) $\mathrm{H}, \mathrm{W}$ error variance by group (a) $\mathrm{H}, \mathrm{W}$ error covariance by group (a)

Note. $\mathrm{H}=$ husband; $\mathrm{W}=$ wife.

To what extent does the husband's and wife's day-to-day anger covary? That is, on days when the husband is more angry than he typically is, is the wife more angry than she typically is?

How much do dyads differ from one another in their mean and variability in $Y$ ? Concrete research questions regarding differences in means are in section (a) in column 2 of Table 1. Do couples differ from one another in mean levels of the husband's anger? That is, are there some couples in which husbands show high levels of daily anger and other couples in which husbands do not? Do couples vary from one another in mean levels of the wife's anger? Finally, we come again to a question that can only be addressed using a dyad design: Are those couples in which husbands show high levels of average anger the same couples in which wives show high levels of average anger, and vice versa?

Concrete research questions regarding differences in variability are in section (b) in column 2 of Table 1 . How much do couples differ from one another in the day-to-day variability of the husband's anger? How much do they differ in the variability of the wife's anger? Finally, how much do couples vary from one another in the covariation of hus- bands' and wives' anger? Are there some couples in which the husband's and wife's daily anger move in close synchrony and other couples in which knowing the husband's anger tells us nothing about the wife's anger (and vice versa)?

What explains between-dyad differences in typical levels of $Y$ ? In this case, we bring the between-couple variable, intervention group, into the analysis. Turning first to questions concerning mean levels, are mean levels of husbands' anger lower for couples in the intervention group than for those in the control group? Are mean levels of wives' anger lower for couples in the intervention group than for those in the control group? What is the correlation between mean husband and wife anger within the intervention and control groups? If the correlation had been appreciable before group was included in the analysis but was reduced after it was introduced, then it can be concluded that part of the original correlation was attributable to the effect of group (whereby, following the intervention, couples with husbands and wives with relatively high levels of anger tended to be in the control group, and couples with husbands and wives with relatively low levels of anger tended to be in the intervention group). 
Table 2

Examples of Research Questions and Statistical Analysis for Time-Based Diary Studies: Modeling the Time Course

Abstract research questions

What is the average dyad's:

(a1) initial level of $\mathrm{Y}$ for member $\mathrm{A}$ initial level of Y for member B

(a2) rate of change in $\mathrm{Y}$ for member $\mathrm{A}$ rate of change in $\mathrm{Y}$ for member $\mathrm{B}$

(b) residual Y variability for member A residual Y variability for member B residual covariation in member A's and B's Y
How much do dyads (co)vary from one another in:

(a1) initial level of $\mathrm{Y}$ for member $\mathrm{A}$ initial level of $Y$ for member $B$ A's and B's initial level of Y

(a2) rate of change in $\mathrm{Y}$ for member $\mathrm{A}$ rate of change in $\mathrm{Y}$ for member $\mathrm{B}$ A's and B's rate of change in $Y$

(b) residual $\mathrm{Y}$ variability for member $\mathrm{A}$ residual $\mathrm{Y}$ variability for member $\mathrm{B}$ residual covariation in member A's and B's Y
What are the sources of between-dyad (co)variability in:

(a1) initial level of $\mathrm{Y}$ for member $\mathrm{A}$ initial level of $\mathrm{Y}$ for member B A's and B's initial level of Y

(a2) rate of change in $Y$ for member $A$ rate of change in $\mathrm{Y}$ for member $\mathrm{B}$ A's and B's rate of change in Y

(b) residual $\mathrm{Y}$ variability for member $\mathrm{A}$ residual $\mathrm{Y}$ variability for member $\mathrm{B}$ residual covariation in member A's and B's Y

Concrete research questions: Daily conflict study

What is the average couple's:

(a1) initial level of H's anger initial level of W's anger

(a2) rate of change in H's anger per day rate of change in W's anger per day

(b) residual variability in H's anger residual variability in W's anger residual covariation in H's and W's anger
How much do couples (co)vary from one another in:

(a1) initial level of H's anger initial level of W's anger H's and W's initial levels

(a2) rate of change in H's anger rate of change in W's anger H's and W's rates of change

(b) residual variability in H's anger residual variability in W's anger residual covariation in H's and W's anger
Can intervention group explain betweencouple (co)variability in:

(a1) initial level of H's anger initial level of W's anger H's and W's initial levels

(a2) rate of change in H's anger rate of change in W's anger H's and W's rates of change

(b) residual variability in H's anger residual variability in W's anger residual covariation in H's and W's anger

\section{Multilevel model}

Level 1: Intercept for $\mathrm{H}$ and $\mathrm{W}$ Time slopes for $\mathrm{H}$ and $\mathrm{W}$

$\mathrm{H}, \mathrm{W}$ error variance (b)

$\mathrm{H}, \mathrm{W}$ error covariance (b)

Level 2: Intercept for $\mathrm{H}$ and $\mathrm{W}$ $\mathrm{H}, \mathrm{W}$ intercept error variance (a1)

$\mathrm{H}, \mathrm{W}$ intercept error covariance

Slopes for $\mathrm{H}$ and $\mathrm{W}$

$\mathrm{H}, \mathrm{W}$ time slope error variance

(a2)

$\mathrm{H}, \mathrm{W}$ time slope error

covariance
Level 1: Intercept for $\mathrm{H}$ and $\mathrm{W}$ Time slopes for $\mathrm{H}$ and $\mathrm{W}$ H,W error variances by couple (b) $\mathrm{H}, \mathrm{W}$ error covariances by couple (b)

Level 2: Intercept for $\mathrm{H}$ and $\mathrm{W}$ H,W intercept error variance (a1) $\mathrm{H}, \mathrm{W}$ intercept error covariance (a1) Slopes for $\mathrm{H}$ and $\mathrm{W}$

$\mathrm{H}, \mathrm{W}$ time slope error variance (a2) $\mathrm{H}, \mathrm{W}$ time slope error covariance (a2)
Level 1: Intercept for $\mathrm{H}$ and $\mathrm{W}$ $\mathrm{H}, \mathrm{W}$ time slopes by group $\mathrm{H}, \mathrm{W}$ error variance by group (b) $\mathrm{H}, \mathrm{W}$ error covariance by group (b)

Level 2: H,W intercept by group (a1) $\mathrm{H}, \mathrm{W}$ intercept error variance by group (a1)

$\mathrm{H}, \mathrm{W}$ intercept error covariance by group (a1)

H,W time slope by group (a2)

$\mathrm{H}, \mathrm{W}$ time slope error variance by group (a2)

$\mathrm{H}, \mathrm{W}$ time slope error covariance by group (a2)

Note. $\mathrm{H}=$ husband; $\mathrm{W}=$ wife.

What explains between-dyad differences in variability? In the case of questions concerning variability, are there differences in day-to-day variability in husbands' anger between the intervention and control groups? Are there differences in day-to-day variability in wives' anger between the intervention and control groups? If the intervention was successful in reducing the escalation of conflicts, then one would expect less variability in the intervention group for both husbands and wives. Finally, do the groups differ in the day-to-day covariation of husbands' and wives' anger? One might expect that intervention group dyads become more skilled at stopping a contagion of anger from one partner to the next.

\section{Modeling the Time Course: How Does Y Change Over Time?}

The next major set of questions, listed in Table 2, concerns the temporal structure of the dyadic diary data. All diary data have a temporal ordering, and it is often of interest to examine this ordering explicitly. For simplicity, we focus on linear change. As before, we focus on the concrete research questions in panel 2 of Table 2.

Level and change for the average dyad (a). The questions in Table 2 concern the simplest and most common approach to modeling change, that is, initial level and linear change. What is the initial level of anger of the husband and 
Table 3

Examples of Research Questions and Statistical Analysis for Time-Based Diary Studies: Modeling the Within-Couple Process

\section{Abstract research questions}

What is the average dyad's:

(a1) level of $\mathrm{Y}$ for $\mathrm{X}=0$ for member $\mathrm{A}$ level of $Y$ for $X=0$ for member $B$

(a2) change in $\mathrm{Y}$ per $\mathrm{X}$ for member $\mathrm{A}$ change in $\mathrm{Y}$ per $\mathrm{X}$ in $\mathrm{Y}$ for member $\mathrm{B}$

(b) residual Y variability for member A residual $\mathrm{Y}$ variability for member $\mathrm{B}$ residual covariation in member A's and B's Y
How much do dyads (co)vary from one another in:

(a1) initial level of $\mathrm{Y}$ for member $\mathrm{A}$ initial level of $Y$ for member $B$ A's and B's initial level of Y

(a2) change in $Y$ per $X$ for member $A$ change in $\mathrm{Y}$ per $\mathrm{X}$ for member $\mathrm{B}$ A's and B's change in Y per X

(b) residual $\mathrm{Y}$ variability for member $\mathrm{A}$ residual $\mathrm{Y}$ variability for member $\mathrm{B}$ residual covariation in member A's and B's Y
What are the sources of between-dyad (co)variability in:

(a1) initial level of $\mathrm{Y}$ for member $\mathrm{A}$ initial level of $Y$ for member B A's and B's initial level of Y

(a2) change in $Y$ per $X$ for member $A$ change in $Y$ per $X$ for member $B$ A's and B's change in $Y$ per $X$

(b) residual $\mathrm{Y}$ variability for member $\mathrm{A}$ residual $\mathrm{Y}$ variability for member $\mathrm{B}$ residual covariation in member A's and B's Y

Concrete research questions: Daily conflict study

What is the average couple's:

(a1) H's anger on days when no conflict occurs

W's anger on days when no conflict occurs

(a2) difference in H's anger between conflict and no-conflict days difference in W's anger between conflict and no-conflict days

(b) residual variability in H's anger residual variability in W's anger residual covariation in H's and W's anger

Level 1: Intercept for $\mathrm{H}$ and $\mathrm{W}$ Conflict slopes for $\mathrm{H}$ and $\mathrm{W}$ Error variance for $\mathrm{H}, \mathrm{W}$ (b)

$\mathrm{H}, \mathrm{W}$ error covariance (b)

Level 2: Intercept for $\mathrm{H}$ and $\mathrm{W}$ (a1) Conflict slopes for $\mathrm{H}$ and $\mathrm{W}$ (a2) Error variance for $\mathrm{H}, \mathrm{W}$

$\mathrm{H}, \mathrm{W}$ error covariance
How much do couples (co)vary from one another in:

(a1) H's anger when no conflict occurs W's anger when no conflict occurs covariance in H's and W's anger when no conflict occurs

(a2) difference in H's anger between conflict and no-conflict days difference in W's anger between conflict and no-conflict days convariance in difference in H's and W's anger between conflict and noconflict days

(b) residual variability in H's anger residual variability in W's anger residual covariation in H's and W's anger
Can Intervention Group explain between- couple (co)variability in:

(a1) H's anger when no conflict occurs W's anger when no conflict occurs covariance in H's and W's anger when no conflict occurs

(a2) difference in H's anger between conflict and no-conflict days difference in W's anger between conflict and no-conflict days covariance in difference in H's and W's anger between conflict and no-conflict days

(b) residual variability in H's anger residual variability in W's anger residual covariation in H's and W's anger
Multilevel model

Level 1: Intercept for $\mathrm{H}$ and $\mathrm{W}$ Rate of change for $\mathrm{H}$ and $\mathrm{W}$ $\mathrm{H}$,W error variance by couple (b) H,W error covariance by couple (b)

Level 2: Intercept for $\mathrm{H}$ and $\mathrm{W}$ $\mathrm{H}, \mathrm{W}$ intercept error variance (a1)

$\mathrm{H}$,W intercept error covariance (a1)

Conflict slopes for $\mathrm{H}$ and $\mathrm{W}$ $\mathrm{H}, \mathrm{W}$ conflict slopes error variance (a2)

$\mathrm{H}, \mathrm{W}$ conflict slopes error covariance (a2)
Level 1: Intercept for $\mathrm{H}$ and $\mathrm{W}$ by group Rate of change for $\mathrm{H}$ and $\mathrm{W}$ by group $\mathrm{H}$, W error variance by group (b) H,W error covariance by group (b)

Level 2: Intercept for $\mathrm{H}$ and $\mathrm{W}$ by group (a1)

$\mathrm{H}, \mathrm{W}$ intercept error variance by group (a1)

$\mathrm{H}, \mathrm{W}$ intercept error covariance by group (a1)

Conflict slopes for $\mathrm{H}$ and $\mathrm{W}$ by group (a2)

$\mathrm{H}$,W slope error variance by group (a2)

H,W slope error covariance by group (a2)

Note. $\mathrm{H}=$ husband; $\mathrm{W}=$ wife

wife in the average dyad? How does the anger of the husband and wife in the average dyad change over time?

Residual variability for the average dyad (b). When temporal change is taken into account, to what extent is there residual day-to-day variability in anger for husbands and wives? If there are strong patterns of linear change in the data, this residual variability may be small relative to the original variability discussed in Table 1. Of perhaps greater interest to marital researchers is the covariance between residual anger for husbands and wives. To the extent to 
Table 4

Example Data Structure for Two Married Couples, One in the Control Group (Group = 0) and One in the Intervention Group (Group = 1)

\begin{tabular}{|c|c|c|c|c|c|c|c|c|c|c|c|c|c|}
\hline Observation & $\begin{array}{l}\text { Couple } \\
\text { ID }\end{array}$ & Group & Husband & Wife & Htime & Wtime & Anger & $\begin{array}{c}\text { Group } \times \\
\text { Htime }\end{array}$ & $\underset{\text { Wtime }}{\text { Group }} \times$ & Hconfl & Wconfl & $\begin{array}{c}\text { Group } \times \\
\text { Hconfl }\end{array}$ & $\underset{\text { Wconfl }}{\text { Group }} \times$ \\
\hline 1 & 001 & 0 & 1 & 0 & 0 & 0 & 3 & 0 & 0 & 0 & 0 & 0 & 0 \\
\hline 2 & 001 & 0 & 1 & 0 & 1 & 0 & 4 & 0 & 0 & 0 & 0 & 0 & 0 \\
\hline 3 & 001 & 0 & 1 & 0 & 2 & 0 & 3 & 0 & 0 & 0 & 0 & 0 & 0 \\
\hline 4 & 001 & 0 & 1 & 0 & 3 & 0 & 6 & 0 & 0 & 1 & 0 & 0 & 0 \\
\hline 5 & 001 & 0 & 1 & 0 & 4 & 0 & 7 & 0 & 0 & 1 & 0 & 0 & 0 \\
\hline 6 & 001 & 0 & 1 & 0 & 5 & 0 & 8 & 0 & 0 & 1 & 0 & 0 & 0 \\
\hline 7 & 001 & 0 & 1 & 0 & 6 & 0 & 5 & 0 & 0 & 0 & 0 & 0 & 0 \\
\hline 8 & 001 & 0 & 0 & 1 & 0 & 0 & 4 & 0 & 0 & 0 & 0 & 0 & 0 \\
\hline 9 & 001 & 0 & 0 & 1 & 0 & 1 & 3 & 0 & 0 & 0 & 0 & 0 & 0 \\
\hline 10 & 001 & 0 & 0 & 1 & 0 & 2 & 4 & 0 & 0 & 0 & 0 & 0 & 0 \\
\hline 11 & 001 & 0 & 0 & 1 & 0 & 3 & 5 & 0 & 0 & 0 & 1 & 0 & 0 \\
\hline 12 & 001 & 0 & 0 & 1 & 0 & 4 & 6 & 0 & 0 & 0 & 1 & 0 & 0 \\
\hline 13 & 001 & 0 & 0 & 1 & 0 & 5 & 5 & 0 & 0 & 0 & 1 & 0 & 0 \\
\hline 14 & 001 & 0 & 0 & 1 & 0 & 6 & 4 & 0 & 0 & 0 & 0 & 0 & 0 \\
\hline 15 & 002 & 1 & 1 & 0 & 0 & 0 & 5 & 0 & 0 & 0 & 0 & 0 & 0 \\
\hline 16 & 002 & 1 & 1 & 0 & 1 & 0 & 6 & 1 & 0 & 0 & 0 & 0 & 0 \\
\hline 17 & 002 & 1 & 1 & 0 & 2 & 0 & 6 & 2 & 0 & 1 & 0 & 1 & 0 \\
\hline 18 & 002 & 1 & 1 & 0 & 3 & 0 & 4 & 3 & 0 & 0 & 0 & 0 & 0 \\
\hline 19 & 002 & 1 & 1 & 0 & 4 & 0 & 5 & 4 & 0 & 0 & 0 & 0 & 0 \\
\hline 20 & 002 & 1 & 1 & 0 & 5 & 0 & 4 & 5 & 0 & 1 & 0 & 1 & 0 \\
\hline 21 & 002 & 1 & 1 & 0 & 6 & 0 & 4 & 6 & 0 & 1 & 0 & 1 & 0 \\
\hline 22 & 002 & 1 & 0 & 1 & 0 & 0 & 2 & 0 & 0 & 0 & 0 & 0 & 0 \\
\hline 23 & 002 & 1 & 0 & 1 & 0 & 1 & 3 & 0 & 1 & 0 & 0 & 0 & 0 \\
\hline 24 & 002 & 1 & 0 & 1 & 0 & 2 & 4 & 0 & 2 & 0 & 1 & 0 & 1 \\
\hline 25 & 002 & 1 & 0 & 1 & 0 & 3 & 3 & 0 & 3 & 0 & 0 & 0 & 0 \\
\hline 26 & 002 & 1 & 0 & 1 & 0 & 4 & 3 & 0 & 4 & 0 & 0 & 0 & 0 \\
\hline 27 & 002 & 1 & 0 & 1 & 0 & 5 & 5 & 0 & 5 & 0 & 1 & 0 & 1 \\
\hline 28 & 002 & 1 & 0 & 1 & 0 & 6 & 4 & 0 & 6 & 0 & 1 & 0 & 1 \\
\hline
\end{tabular}

Note. Anger scores range from 1-10. Htime $=$ the effect of time for husbands; Wtime $=$ the effect of time for wives; Hconfl $=$ the effect of daily conflict for husbands; Wconfl = the effect of daily conflict for wives.

which the original covariation discussed in Table 1 is attributable to common patterns of linear change over time, the smaller the residual covariance will be.

Between-dyad differences in initial level and change (a). The second column of Table 2 is concerned with betweencouple differences in initial levels and rates of change. To what extent are there differences between couples in the initial level of anger for husbands and for wives? In couples where husbands have high initial anger (relative to other couples), do wives also have similarly high initial anger? The same questions apply to rates of change. Are there substantial between-couple differences in change for husbands and wives, and are those husbands with steep rates of change paired with wives who also show steep rates of change.

Between-dyad differences in residual variability (b). Here, we are concerned with differences between couples in the "left-over" variance in anger for husbands and wives, after the linear effect of time has been removed. An interesting potential result would be that original heterogeneity in this variance, discussed in Table 1, may be eliminated when the differential effects of time are taken into account. That is, husbands and wives in some couples may have shown greater original variability than those in other couples because their anger changed more over time. Finally, we examine between-couple differences in the covariance of residual anger. Again, it may be that between-couple differences in husband-wife covariance in day-to-day anger is attributable to between-couple differences in the effects of time on anger for husbands and wives.

Explaining between-dyad differences. The final column of questions in Table 2 refers to an explanatory account of between-dyad differences. What accounts for between-dyad differences in initial level and rate of change of anger for males and females? What accounts for the between-couple covariance in the initial levels of anger of males and females? What accounts for the between-couple covariance in rates of change in anger for males and females?

\section{Modeling Within-Dyad Processes: What Explains Changes Over Time?}

The trajectory of change over time is likely to be governed by many factors, some of which are common to the couple, such as daily conflicts (e.g., arguments, disagreements, tensions), and others that pertain to particular members of the couple (e.g., problems in the workplace). For the sake of simplicity, we focus on only one factor, one that is common to both members, namely, the occurrence of a conflict within the couple on a given day. Analogous to Tables 1 and 2, Table 3 contains the list of research questions pertaining to (a) within-couple processes in the typical 
couple, (b) the existence of between-couple differences in these within-couple processes, and (c) variables that might explain these between-couple differences. As before, we use intervention group as the between-couple explanatory variable for our research example. Thus, in the case of daily conflicts as a within-couple explanatory variable, we would be interested in seeing whether, for example, conflicts explained variance and covariance in husbands' and wives' daily anger and whether intervention group explained differences between couples in husbands' and wives' reactivity to conflicts.

\section{Types of Diary Designs}

The types of research questions outlined above can be addressed using one of three general categories of diary methods utilized and reviewed in the literature (Eckenrode \& Bolger, 1995; Wheeler \& Reis, 1991). The first is known as interval-contingent recording. When using this method, spouses or family members record experiences at regular and predetermined intervals of time (e.g., every evening), as selected by the researcher. The researchers may want participants to report on the basis of what has occurred since the last recording or on what the participant may be doing or feeling at the moment. The second category of diary methods is known as signal-contingent recording. In contrast to interval-contingent recording, where participants report experiences at regular, predetermined intervals (e.g., one recording per day), signal-contingent recording occurs whenever the participant is contacted by the researcher. The researcher determines whether the intervals are fixed or random, and participants usually report on the experience at that point in time. The third category of daily self-report procedure is event-contingent recording. In this method, participants are asked to report every time a preestablished and predefined event has taken place. For example, the Rochester Interaction Record (RIR; Reis \& Wheeler, 1991; Wheeler \& Nezlek, 1977) and the Iowa Communication Record (ICR; Duck, 1991) are two types of eventcontingent recording diaries that have been used to address questions concerning the quality and nature of social interactions. The signaling event can be a conflict, an interaction with a particular partner (e.g., spouse, mother/father), or a particular positive or negative event. It is important that the event be well defined and concrete enough so that participants can provide a valid sampling of events.

\section{Technological Issues}

Paper-and-pencil diary implementation. One implementation of diary methods consists of participants carrying around packets of paper-and-pencil diary forms on which to record responses. For example, immediately following a social interaction, participants might be asked to answer questions on a form concerning the quality and nature of the interaction the participant just had (Reis \& Wheeler, 1991; Wheeler \& Nezlek, 1977). Rating forms can be used in combination with pagers or preprogrammed watches, where participants complete forms at specified or randomly sig- naled times (e.g., McAdams \& Constantian, 1983). It is clear that some version of the paper-and-pencil forms is the easiest when implementing a diary study. The limitations of paper-and-pencil diary approaches have been discussed by some researchers (e.g., Shiffman, Hufford, \& Paty, 2001) and include participant forgetfulness, uncertain compliance, data entry burden, and confidentiality of diary forms. Nevertheless, for some diary studies (e.g., event-contingent diary sampling), paper-and-pencil methods can be effectively implemented, following suggestions detailed in Bolger et al. (2003).

Computerized diary implementation. The past decade has heralded the development of electronic palm-top devices for implementing diary studies. These palm-top devices, also known as Personal Digital Assistants (PDAs), are essentially hand-held computers that present customdesigned questions where responses are collected in a database program that is running in the background. With the proliferation of PDA device use, there are PDA software programs that have been developed specifically to conduct diary studies. One software package that is readily available and that may prove useful to marital and family researchers wanting to conduct diary studies is Barrett and Feldman Barrett's (2000) Experience Sampling Program (ESP). ESP is a free and user-friendly program for running basic diary studies on PDAs with little or no software programming experience. Useful features of ESP include the ability to (a) run interval-contingent (e.g., daily), signal-contingent (e.g., random signals), or event-contingent (e.g., after a marital conflict) diary protocols; (b) present randomly diary items for one block of items; (c) take over the machine so the participant does not have access to other programs on the device; (d) control the time that participants have to respond to diary prompts or diary items; and (e) present a time-date stamp that is automatically linked to each diary entry. The developers of ESP are also planning further updates and enhancements to the ESP software to incorporate other features such as a back button and branching capabilities (where presentation of items depend on answers to a previous item).

Overall, the benefits of computerized diary methods include tracking compliance with planned diary design, allowing control of the presentation of items (e.g., signaling, randomizing), and reducing the diary data entry and management burden. Moreover, an increasing number of participants in this computerized day and age may be more familiar with, and motivated to use, a PDA device for diary study participation.

\section{Data-Analytic Issues}

We now return to the example study and the dataset illustrated in Table 4. A key variable in the dataset is couple ID, which uniquely identifies all the observations from a particular couple. Note that although there are observations for each person and each day within a couple, the fundamental unit of analysis is the couple. Couples are assumed to be independently sampled, but once a couple is sampled, the persons and days within each couple are treated as 
nonindependent. Nonindependence of observations leads to biased tests of significance, and in most cases, the bias is in the direction of falsely rejecting the null hypothesis for those statistical tests assuming independence of observations (Kenny, Kashy, \& Bolger, 1998). To deal with this problem, diary researchers need to use relatively complex multilevel analysis models (Raudenbush \& Bryk, 2002; Snijders \& Bosker, 1999).

\section{Why Not Analyze Dyad Members Separately?}

One solution to the problem of nonindependence in dyads is to analyze the data from each role member separately. Thus, one could investigate daily anger in male partners in a multilevel model that is separate from the equivalent multilevel model for female partners. Although statistically valid, such an approach rules out the investigation of many interesting questions discussed earlier, and in particular, the ones that are unique to dyadic diary data. Thus, one cannot examine within-dyad covariation in anger for male and female partners and whether certain processes (e.g., shared stressors, emotional contagion) could explain this covariation. In addition, one cannot examine between-dyad covariation in average levels of male and female anger and whether certain dyadic factors (e.g., relationship quality, length of relationship) could explain this covariation. In general, this data analytic approach is not recommended because it precludes examining the inherent nonindependence between male and female partner variables in dyadic data.

\section{Data Analysis Model: Two or Three Levels?}

Considering that diary data in distinguishable dyads have three levels of analysis - the dyad, the persons within the dyad, and the observations within the persons-it may seem obvious that such data should be analyzed using a threelevel model. In fact, we believe this is rarely, if ever, a good idea.

The central idea underlying multilevel models is that there can be probabilistic variability at each level. However, in the case of distinguishable dyads, once role within the dyad (e.g., wife vs. husband, mother vs. child) is included in the model, there can be no estimate of additional variability at the middle level. The model is said to be saturated at the middle level (see Diggle, Heagarty, Liang, \& Zeger, 2002, p. 65 , for a discussion of this problem in the context of longitudinal data analysis). A way to think about it is that, whereas there is sampling of couples, there are only two partners per couple, resulting in two observations at the middle level. Therefore, this means there can be no predictors of between-person variability beyond, of course, the variable that defines role. The solution to this problem is to abandon the idea of estimating a three-level model and to formulate it as a two-level one, as is discussed in the next section.

\section{Dyadic Analysis Model}

The two-level multilevel model we recommend was first introduced by Raudenbush, Brennan, and Barnett (1995) as part of a more complex model for longitudinal dyadic data. It also draws on work by Kenny and Zautra (1995) and Gonzalez and Griffin (2000).

Below, we present an account of how this model can be implemented to answer the questions presented in Tables 1 and 2. Our account is necessarily brief and is likely to be most useful to readers who are already familiar with multilevel models for diary data on individuals (for a review, see Bolger et al., 2003; Raudenbush \& Bryk, 2002).

To understand the Raudenbush et al. (1995) model it is critical to know the way dyadic data need to be structured before analysis can begin. As noted, Table 4 shows data for 7 days for each partner in two couples. Each couple contributes 14 observations (data lines) to the dataset, resulting in 28 total observations. Crucial to understanding the Raudenbush et al. (1995) analysis model is the idea that husbands and wives have unique predictor variables. Thus, for husbands, we have a dummy-coded variable called husband, which captures the effect of the husband's intercept, a variable called Htime, which captures the effect of time for husbands, and a variable called Hconfl, which captures the effect of daily conflicts for husbands. We have equivalent variables for wives: a wife dummy variable; Wtime, capturing the effect of time for wives; and Wconfl, capturing the effect of daily conflicts for wives.

Husband and Wife are perfectly negatively correlated, as are Htime and Wtime and Hconfl and Wconfl. Although it may seem strange to those who are not used to this data structure, models can be estimated with both the husband and wife dummy variables included as predictors (and the other pairs also), as long as one specifies a model without the customary intercept term. All standard multilevel analysis programs allow the analyst to omit the intercept term.

Aggregation model. To estimate the aggregation model discussed in Table 1, we specify a multilevel model where, at Level 1, the daily level, one includes husband and wife as predictors of anger (and one omits the intercept). These predictors allow for a separate mean level (i.e., intercept) for male and female members of each dyad. One also allows for correlated residuals at Level 1 such that, on days when a husband's anger is high relative to his average across days, his wife's anger is similarly high. Finally, different Level 1 residual variances are estimated for husbands and wives. Examples of this error specification and details on how it can be implemented in PROC MIXED in SAS can be seen in articles by Gleason, Iida, Bolger, and Shrout (2003) and Kennedy, Bolger, and Shrout (2002). The model can be further complicated by allowing for separate Level 1 residual variances for each couple.

At Level 2 of the multilevel model, one specifies that there is an average Husband effect and average wife effect across couples and that each husband and wife is allowed a specific residual (deviation) from the overall means. One also allows for a correlation between these residuals from the means for husbands and wives. Thus, it is possible to 
examine whether husbands whose mean anger is relatively high are paired with wives whose mean anger is also relatively high.

To investigate whether intervention group explains between-couple differences in means, variances, and covariances, one adds group as a predictor at Level 2, and one also allows for separate variances and covariances by group.

Modeling the time course. Modeling the time course is accomplished by adding Mtime and Wtime to the Level 1 model, thereby estimating an intercept (initial level) and time (rate of change) effect for husbands and wives. One can also allow Level 1 error variances to differ by husband and wife and by couple. At Level 2, one estimates an average intercept and slope for husbands and for wives, and one again allows for couple-level residuals from these averages. To explain between-couple differences in intercepts and rates of change, one includes group as a predictor at Level 2.

Modeling the within-couple process. Here, instead of Htime and Wtime as Level 1 predictors, one uses Hconfl and Wconfl. This allows for conflict to have different effects for husbands and wives in each couple. The error structure at Level 1 again allows for separate variances for husbands and wives and for a husband-wife covariance. These variances and covariances can be allowed to be different for different couples.

At Level 2, one estimates an average Husband and Hconfl effect and an average Wife and Wconfl effect, and one allows for couple-level residuals from these averages. These residuals are allowed to correlate such that one can determine whether, for example, couples where husbands are reactive to conflicts are paired with wives who are similarly reactive to conflicts. Finally, one can include group as a Level 2 predictor to determine whether couple-level variability in these effects is explained by intervention group, as one might expect it to be.

\section{Unresolved Issues and Directions for Future Research}

Diary methods allow researchers to study marital and family processes within the context of daily life in a way that is not possible with more traditional methods. Marital and family researchers can use these methods to address new questions and to revisit old questions with a new tool. Although diary methods represent an important and emerging methodological approach, there are still unresolved issues. Because of space limitations, we raise two here that merit further attention in future work.

\section{Paper-and-Pencil Versus Electronic Diaries: Is Electronic Always Better?}

As noted in an earlier portion of this article, technological advances have allowed researchers using diary methods to use an electronic format for data collection. On the basis of findings from a study comparing electronic and paper-andpencil formats, Stone, Shiffman, Schwartz, Broderick, and Hufford (2002) have argued that compliance is poor with paper-and-pencil formats, resulting in unreliable data. These findings may lead to the premature conclusion that computerized diary methods are the only way to obtain valid diary data and that findings from past diary studies using paperand-pencil methods may be called into question. Recently, Green, Rafaeli, Bolger, and Shrout (2004) reported on the results of two diary studies, each comparing the use of computerized and paper-and-pencil modes. Findings from both studies suggest that both modes of data collection are viable and produce data that are psychometrically comparable. So, when should a paper-and-pencil format be used? Green et al. (2004) argue that reducing participant demand and using an alternative assessment of compliance can increase the procurement of viable paper-and-pencil data. Moreover, if the timing of recording is important for the variables of interest (i.e., waking and sleeping times of an infant child) and they are assessed multiple times a day, a computerized format with a time-date stamp would be preferable. However, if items are asked once a day and occur at the same time each day (in the evening, before bedtime), a paper-and-pencil format may be easier to implement, less burdensome for the participant, and able to produce reliable data.

Nevertheless, further issues related to the comparability of paper-and-pencil versus computerized diary formats remain. Are there other conditions under which data obtained from one format versus another differ? Are there individual difference factors that may influence whether a participant would provide more accurate data in one or the other format? Does the ability to randomize the presentation of items or to change the order of item presentation between diary entries in computerized formats produce equivalent data to paper-and-pencil diaries where item presentation is typically the same? Questions such as these remain ripe for future work.

\section{Potential Effects of Diary Method Participation on Marriages/Families}

Given the likely increase in the use of diary methods, little attention has been focused on the possibility that diary method participation may have unintended negative or positive effects on the perceptions and evaluations of marriage/ family members. Because of the intensive nature of assessments, diary-type designs may focus attention to aspects of relationship experiences to a greater degree than do traditional cross-sectional or longitudinal designs. For example, completing multiple diary items focused on relationship positive and negative events may increase awareness of the strengths of a marital relationship, or it may lead to increased awareness and rumination about conflict or relationship weaknesses. However, some recent work is beginning to address this issue. Across three independent samples, Acevedo and Laurenceau (2004) found that married and romantic couples expressed positive reactions to diary method participation, little change in perceived relationship conflict, and nonsignificant pre-to-post changes across several measures of relationship functioning. However, limitations of this work include the lack of a nondiary control 
group, differing diary lengths across samples, and differing diary methods (interval contingent vs. event contingent). We recommend that future works attempt to replicate these findings as well as explore other conditions (e.g., marital length, distressed vs. nondistressed status) under which diary research may have unintended negative effects on the marriages and the families that participate.

\section{References}

Acevedo, M., \& Laurenceau, J.-P. (2004). Examining the potential effects of diary method participation on marital and dating relationships. Manuscript submitted for publication.

Adams, C. R. (1946). The prediction of adjustment in marriage. Educational and Psychological Measurement, 6, 185-193.

Barrett, D. J., \& Feldman Barrett, L. (2000). ESP: The Experience Sampling Program [Computer software and manual]. Retrieved from http://www2.bc.edu/ barretli/esp/

Bentler, P. M., \& Newcomb, M. D. (1978). Longitudinal study of marital success and failure. Journal of Consulting and Clinical Psychology, 47, 368-376.

Bolger, N., Davis, A., \& Rafaeli, E. (2003). Diary methods: Capturing live as it is lived. Annual Review of Psychology, 54, 579-616.

Bolger, N., \& Schilling, E. A. (1991). Personality and the problems of everyday life: The role of neuroticism in exposure and reactivity to daily stressors. Journal of Personality, 59, 355-386.

Bolger, N., \& Zuckerman, A. (1995). A framework for studying personality in the stress process. Journal of Personality and Social Psychology, 69, 890-902.

Borsboom, D., Mellenbergh, G. J., \& van Heerden, J. (2003). The theoretical status of latent variables. Psychological Review, 110, 203-219.

Csikszentmihalyi, M., \& Larson, R. (1984). Being adolescent: Conflict and growth in the teenage years. New York: Basic Books.

Csikszentmihalyi, M., Larson, R., \& Prescott, S. (1977). The ecology of adolescent activity and experience. Journal of Youth and Adolescence, 6, 281-294.

Cummings, E. M., Goeke-Morey, M. C., Papp, L. M., \& Dukewich, T. L. (2002). Children's responses to mothers' and fathers' emotionality and tactics in marital conflict in the home. Journal of Family Psychology, 16, 478-492.

Diener, E., \& Emmons, R. A. (1985). The independence of positive and negative affect. Journal of Personality and Social Psychology, 47, 1105-1117.

Diener, E., \& Larsen, R. J. (1984). Temporal stability and crosssituational consistency of affective, cognitive, and behavioral responses. Journal of Personality and Social Psychology, 47, 871-883.

Diggle, P. J., Heagarty, P., Liang, K. Y., \& Zeger, S. L. (2002). Analysis of longitudinal data (2nd ed.). New York: Oxford University Press.

Duck, S. W. (1991). Diaries and logs. In B. M. Montgomery \& S. W. Duck (Eds.), Studying social interaction (pp. 141-161). New York: Guilford Press.

Duck, S. W., \& Sants, H. K. A. (1983). On the origins of the specious: Are personal relationships really interpersonal states? Journal of Clinical and Social Psychology, 1, 27-41.

Eckenrode, J., \& Bolger, N. (1995). Daily and within-day event measurement. In S. Cohen, R. C. Kessler, \& L. U. Gordon (Eds.), Measuring stress: A guide for health and social scientists (pp. 80-101). New York: Oxford University Press.

Gleason, M. E. J., Iida, M., Bolger, N., \& Shrout, P. E. (2003).
Daily supportive equity in close relationships. Personality and Social Psychology Bulletin, 29, 1036-1045.

Gonzalez, R., \& Griffin, D. (2000). On the statistics of interdependence: Treating dyadic data with respect. In W. Ickes \& S. Duck (Eds.), The social psychology of personal relationships (pp. 181-213). Chichester, England: Wiley.

Gottman, J. M. (1979). Marital interaction: Experimental investigations. New York: Academic Press.

Gottman, J. M., \& Notarius, C. I. (2000). Decade review: Observing marital interaction. Journal of Marriage and the Family, 62, 927-947.

Green, A. S., Rafaeli, E., Bolger, N., \& Shrout, P. E. (2004). Paper or plastic? Data equivalence in paper and electronic diaries. Manuscript submitted for publication.

Halford, W. K., Gravestock, F. M., Lowe, R., \& Scheldt, S. (1992). Towards a behavioural ecology of stressful marital interactions. Behavioral Assessment, 14, 199-217.

Holmes, J. G., \& Murray, S. L. (1996). Interpersonal conflict in close relationships. In E. T. Higgins \& A. W. Kruglanski (Eds.), Social psychology: Handbook of basic mechanisms and processes (pp. 622-654). New York: Guilford Press.

Karney, B. R., \& Bradbury, T. N. (1995). The longitudinal course of marital quality and stability: A review of theory, method, and research. Psychological Bulletin, 118, 3-34.

Karney, B. R., \& Bradbury, T. N. (1997). Neuroticism, marital interaction, and the trajectory of marital satisfaction. Journal of Personality and Social Psychology, 72, 1075-1092.

Karney, B. R., \& Bradbury, T. N. (2000). Attributions in marriage: State or trait? A growth curve analysis. Journal of Personality and Social Psychology, 78, 295-309.

Kelly, E. L., \& Conley, J. J. (1987). Personality and compatibility: A prospective analysis of marital stability and marital satisfaction. Journal of Personality and Social Psychology, 52, 27-40.

Kennedy, J., Bolger, N., \& Shrout, P. (2002). Witnessing interparental psychological aggression in childhood: Implications for daily conflict in adult intimate relationships. Journal of Personality, 70, 1051-1077.

Kenny, D. A., Kashy, D. A., \& Bolger, N. (1998). Data analysis in social psychology. In D. T. Gilbert, S. T. Fiske, et al. (Eds.), The handbook of social psychology (4th ed., pp. 233-265). New York: McGraw-Hill.

Kenny, D. A., Kashy, D. A., \& Cook, W. L. (2005). Dyadic data analysis. New York: Guilford Press.

Kenny, D. A., \& Zautra, A. (1995). The trait-state-error model for multiwave data. Journal of Consulting and Clinical Psychology, $63,52-59$.

Larson, R. W., Richards, M. H., \& Perry-Jenkins, M. (1994). Divergent worlds: The daily emotional experience of mothers and fathers in the domestic and public spheres. Journal of Personality and Social Psychology, 67, 1034-1046.

Laurenceau, J.-P., Feldman Barrett, L., \& Rovine, M. J. (in press). The Interpersonal Process Model of Intimacy in Marriage: A daily-diary and multilevel modeling approach. Journal of Family Psychology.

Margolin, G., Christensen, A., \& John, R. S. (1996). The continuance and spillover of everyday tensions in distressed and nondistressed families. Journal of Family Psychology, 10, 304-321.

McAdams, D. P., \& Constantian, C. A. (1983). Intimacy and affiliation motives in daily living: An experience sampling analysis. Journal of Personality and Social Psychology, 45, 851861.

Parke, R. D. (2004). Development in the family. Annual Review of Psychology, 55, 365-399.

Perrez, M., Schoebi, D., Wilhelm, P. (2000). How to assess social 
regulation of stress and emotions in daily family life? A computer-assisted family self-monitoring system (FASEM-C). Clinical Psychology and Psychotherapy, 7, 326-339.

Raudenbush, S. W., Brennan, R. T., \& Barnett, R. C. (1995). A multivariate hierarchical model for studying psychological change within married couples. Journal of Family Psychology, 9, 161-174.

Raudenbush, S. W., \& Bryk, A. S. (2002). Hierarchical linear models: Applications and data analysis methods (2nd ed.). Thousand Oaks, CA: Sage.

Reis, H. T. (1994). Domains of experience: Investigating relationship processes from three perspectives. In R. Erber \& R. Gilmore (Eds.), Theoretical frameworks in personal relationships (pp. 87-110). Hillsdale, NJ: Erlbaum.

Reis, H. T., \& Gable, S. L. (2000). Event sampling and other methods for studying daily experience. In H. T. Reis \& C. M. Judd (Eds.), Handbook of research methods in social and personality psychology (pp. 190-222). New York: Cambridge University Press.

Reis, H. T., \& Wheeler, L. (1991). Studying social interaction with the Rochester Interaction Record. In M. P. Zanna (Ed.), Advances in experimental social psychology (Vol. 24, pp. 270318). San Diego, CA: Academic Press.

Repetti, R. L. (1989). Effects of daily workload on subsequent behavior during marital interaction: The roles of social withdrawal and spouse support. Journal of Personality and Social Psychology, 57, 651-659.

Repetti, R. L., \& Wood, J. (1997). Effects of daily stress at work on mothers' interactions with preschoolers. Journal of Family Psychology, 11, 90-108.
Shiffman, S., Hufford, M., \& Paty, J. (2001). Subject experience diaries in clinical research: Part 1. The patient experience movement. Applied Clinical Trials, 10, 46-56.

Snijders, T., \& Bosker, R. (1999). Multilevel analysis: An introduction to basic and advanced multilevel modeling. London: Sage.

Stone, A. A., Shiffman, S. S., \& DeVries, M. (1999). Rethinking our self-report assessment methodologies: An argument for collecting ecologically valid, momentary measurements. In D. Kahneman, E. Diener, \& N. Schwarz (Eds.), Well-being: The foundations of hedonic psychology (pp. 26-39). New York: Sage.

Stone, A. A., Shiffman, S., Schwartz, J. E., Broderick, J. E., \& Hufford, M. R. (2002). Patient non-compliance with paper diaries. British Medical Journal, 324, 1193-1194.

Wheeler, L., \& Nezlek, J. (1977). Sex differences in social participation. Journal of Personality and Social Psychology, 35, 742754.

Wheeler, L., \& Reis, H. T. (1991). Self-recording of everyday events: Origins, types, and uses. Journal of Personality, 59, $339-354$.

Wills, T. A., Weiss, R. L., \& Patterson, G. R. (1974). A behavioral analysis of the determinants of marital satisfaction. Journal of Consulting and Clinical Psychology, 42, 802-811.

Received February 25, 2004

Revision received August 30, 2004

Accepted October 12, 2004

\section{Low Publication Prices for APA Members and Affiliates}

Keeping you up-to-date. All APA Fellows, Members, Associates, and Student Affiliates receive-as part of their annual dues-subscriptions to the American Psychologist and APA Monitor. High School Teacher and International Affiliates receive subscriptions to the APA Monitor, and they may subscribe to the American Psychologist at a significantly reduced rate. In addition, all Members and Student Affiliates are eligible for savings of up to $60 \%$ (plus a journal credit) on all other APA journals, as well as significant discounts on subscriptions from cooperating societies and publishers (e.g., the American Association for Counseling and Development, Academic Press, and Human Sciences Press).

Essential resources. APA members and affiliates receive special rates for purchases of APA books, including the Publication Manual of the American Psychological Association, and on dozens of new topical books each year.

Other benefits of membership. Membership in APA also provides eligibility for competitive insurance plans, continuing education programs, reduced APA convention fees, and specialty divisions.

More information. Write to American Psychological Association, Membership Services, 750 First Street, NE, Washington, DC 20002-4242. 